\title{
Developing Mobile Apps Technology to Improve Student Performance in Physical Education
}

\author{
Ipang Setiawan ${ }^{1}$, Wahyu Ragil Kurniawan ${ }^{2}$, Dwi Gansar Santi Wijayanti ${ }^{3}$, \\ Bhayu Billiandri ${ }^{4}$ \\ \{Ipang_setiawan@mail.unnes.ac.id ${ }^{1}$,wahyuragil@mail.unnes.ac.id ${ }^{2}$, \\ dwigansarsanti@mail.unnes.ac.id ${ }^{3}$ \}
}

Universitas Negeri Semarang, Semarang, Indonesia ${ }^{1,2,3,4}$

\begin{abstract}
The purpose of this study is in order to respond to universal challenges to discuss effective assessment designs by utilizing new technologies in physical education. This study was conducted on PE teachers, students, and parents, by taking into account their experiences in using application products. The methods used to support the development process: (1) Determine content; (2) choose an apps platform; 3) Design product; (4) Test the Prototype. Results in this study are the design of mobile application products to improve students in physical education lessons. The prototype was evaluated by parents, students, and PE teachers as users. Conclusion is smartphone applications may be an innovative medium for intervening in change and students' abilities in learning physical education. This research can be made as a basic for further research to create a mobile application in physical education.
\end{abstract}

Keywords: mobile application, learning outcomes, physical education, authentic assessment

\section{Introduction}

Mobile technologies are one of the most popular things today. Various groups ranging from workers until students have used it. However, there are still many teachers who do not yet know about how mobile technologies can affect the learning outcomes. This will be a big problem if not addressed, because the teaching practice of teachers is greatly influenced by their understanding and skills [1]. Providing an authentic assessment is one of the huge problems that are still faced by physical education teachers. How to determine the learning objectives have been achieved, what competencies that students must master in physical education, until how they must provide continuous and appropriate assessment to students, are problems that must be resolved by physical education teacher[2]. Assessment that refers to the process is very important because the teacher can see how students are able to make decisions and assess the best performance in every material they learn. 
giving feedback is very important in achieving the learning outcomes [3]. However, there are some problems that still faced by PE teacher, there are: teacher cannot provide feedback directly to students at the time, cannot easily report student learning outcomes to parents or other teachers, and the teacher also cannot access student performances in class regularly. Some alternative tools and systems databases can do this work for now, but it is not simple enough. A laptop with size that is less practical if brought while teaching in the field. Therefore, teachers usually use a basic list first on paper then send data to the system later. This makes the process slow and inefficient[3]. Some studies have tried to promote a model for evaluating learning outcomes and giving feedback through technology, by integrating instruments and needs analysis in the field.

Technology plays a role as a tool in education, to advance the relationship between students and educators, reduce the gaps associated with finding support resources in learning, and technology also greatly helps meet the needs of students [4]. To compete in this century, teachers must be able to keep abreast of technological developments by being able to create, grow, and be able to use innovative mobile technology, to make education more sophisticated and modern accessible to anyone and at any time. [5]. Very important to know, because an effective Learning environment with technology is created by people, not technologies. Teachers and students who are aware of this development then will issue and want to use it, so they can change and enhance their educational experience in the current era of technological development [6].

Mobile application technology is not only used to achieve maximum learning outcomes, but also used as a provider of data information available at any time. Mobil application technology is considered as a practical and easy alternative to carry anywhere. Related with the description, this study supports to overcome the problem by supporting mobile applications to improve learning outcomes. Practically, found in the MGMP Junior High School, Physical Education teacher association. With detailed procedures, the prototype was tested, while its validation was carried out by the questionnaire filling method. This study will consider case study research where the research will be the basis for further improvement and development.

\section{$2 \quad$ Related Studies}

\subsection{Developing a digital assessment in senior secondary physical education}


This study was conducted to inform the development of Physical Education in Western Australia incorporating practical and / or performance dimensions. This research investigates various types of authentic digital assessments that can be improved for implementation across countries in an easy and inexpensive way. the purpose of this study is to provide insight into physical education teachers to be able to design authentic assessment tasks to be able to see student achievement. The result of this study, students like the way in which the 'practical' and 'theoretical' aspects are combined in the assignments given by the teacher in physical education. PE teacher agrees to be able to design authentic assessment tools that are in line with the teacher's pedagogical abilities. and the tools expected to be able to assess students' knowledge and skills. [2].

\subsection{Development of Smartphone Applications for Nutrition and Physical Activity Behavior Change}

This study discusses four applications that aim to modify lifestyle behaviors associated with weight gain, physical activity, and consumption of foods, fruits, vegetables, and drinks with sugar sweeteners. Requires 18 months to develop this application. after it was finished, the application was tested on 10 subjects, and various responses were obtained including the slow speed of the application network due to the dependence on the Internet connection which was the main problem identified by the research team. Smartphone applications can be an alternative tool that can change a person's healthy behavior, while still paying attention to the number of subjects tested and the strength of the network connection, as well as the app's feasibility to be used for a long period. [7].

\subsection{Instructional Tools for Online Physical Education: Using Mobile Technolo- gies to Enhance Learning}

The results of this study, explained that the use of applications or technology in education has not fully reached the point of maximum benefit, instead it gave rise to negative results. one of them is the lack of an effective and efficient system. so It is necessary to become a particular focus of future researchers, that how to design a technology application that can indeed provide an effective and efficient element is very important. do not let the application developed in the context of physical activity, it actually causes the saturation of the students in their activities. so there needs to be a synchronization between the concept of content, and the expected outputs in designing an application concept in terms of observing a person's behavior or physical activity. [8].

\section{Research Design}


Design and development are used in this study. We define this research as a "systematic study of the design, development and evaluation process with the aim of establishing an empirical basis for creating new and improved learning products and tools as well as models that govern the development of learning systems especially in physical education."'[9]. The questionnaire through the Google form is used to collect data filled in by users or test subjects. This questionnaire is used to discuss the opinions of physical education teachers, students and parents on the use of smartphones and the design of mobile applications to support physical education learning. Descriptive statistics are used to illustrate participants and design the applications they will use. Describing quantitative data done to explore the perspectives of physical education teachers, students, and parents perspectives on the mobile way applications that support student learning and the best ways to apply in practice [10]. 


\subsection{Context of the study}

This focuses study is the developing application design that can be used as an alternative assessment and feedback tool in physical education. The design created includes all domains that exist in physical education, namely cognitive, affective, and psychomotor. The focus of this study is to develop a prototype design of physical education assessment and feedback applications, and test the prototype to users, there are; physical education teachers, students, and parents. The main factor that is the flagship of this prototype is the involvement of communication between teachers, students, parents, and the completeness of the cognitive, affective, and psychomotor domains that are in one hand. The expected research results are the existence of support and positive responses from users to be able to realize the prototype to the next research in the future

\subsection{Participants}

Participant tests were occurred in two phases. The initial phase ; 15 PE Teachers in 15 different junior high schools in Semarang City, Central Java, Indonesia. 15 students from grade 7,8, and 9, and 15 parents. Initial testing is carried out to correct usability problems with the initial design, by asking participants to try the prototype and carry out the basic tasks that have been set in it. Then they provide comments and suggestions via the Google form provided. Then apps modified based on suggestion and evaluation from the first test. While the second phase, a retrial was conducted on 30 PE teachers, 30 students, and 30 parents. By providing a prototype link for use the prototype, and all of the participants would give an evaluation, suggestion, also comments using google form provided

\subsection{Procedure and survey instrument}

The methods used to support the development process: (1) Determine content; (2) choose an apps platform; 3) Design product; (4) Test the Prototype

\section{Stage 1: Determine content}

The first stage of this process involves defining the purpose of this application. This is needed to determine what is relevant to assessment and evaluation in physical education, specific strategies for cognitive, behavioral, and performance change, visual or graphic design, and potential data to be collected such as: curriculum, quizzes for cognitive evaluation, indicators behavior, and skills that must be mastered by students.

\section{Stage 2: Choose an apps platform}

Second stage, the selection platform to be used in this product. This is based on the majority of user resources in the Semarang, Central Java, Indonesia. Generaly they are familiar and exist in using android smartphones. Ease to use is a priority, then based on surveys, application design platforms that are used is android.

\section{Stage 3: Design product}


The design focused on ease to use and minimize color combination. BESCOPER is the name of the design apps developed in this study, the elements in it are the three domains of physical education; Cognitive, Affective, and Psychomotor.

Following are the appearance designs and contents of BESCOPER apps: 


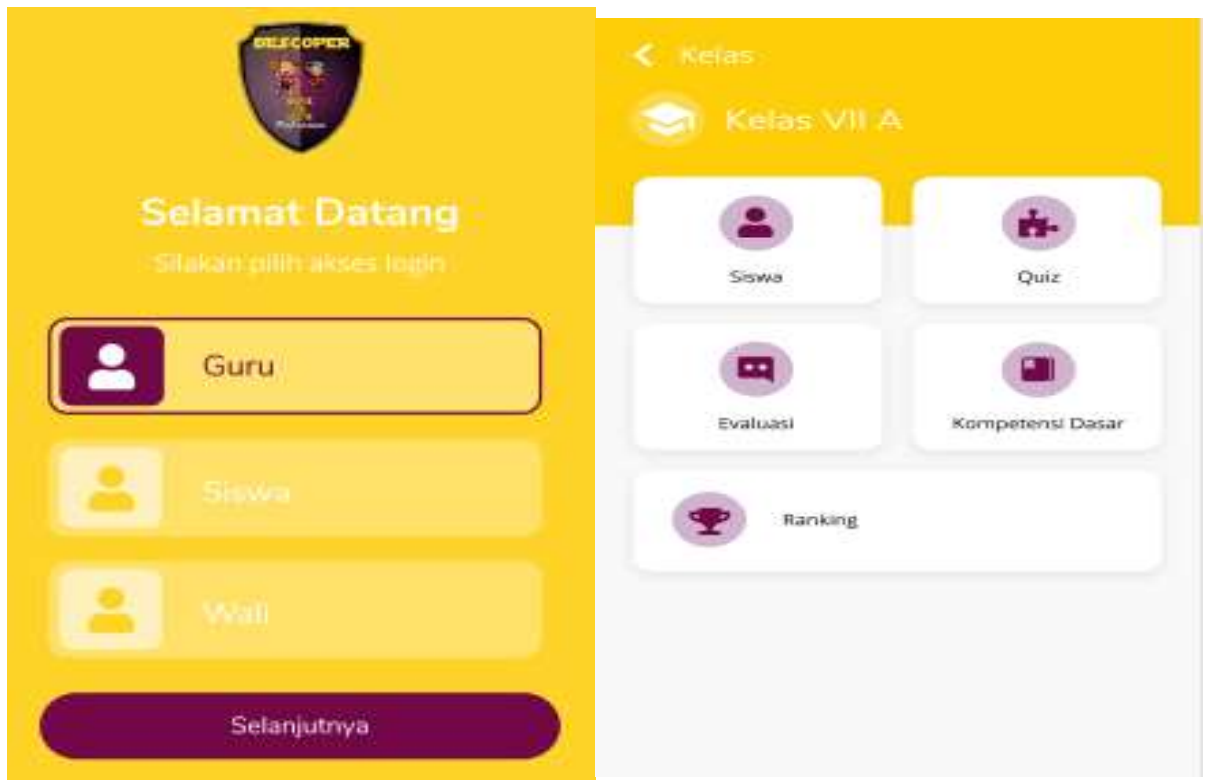

Fig.1. Display login menu

Fig.2. Optional menu

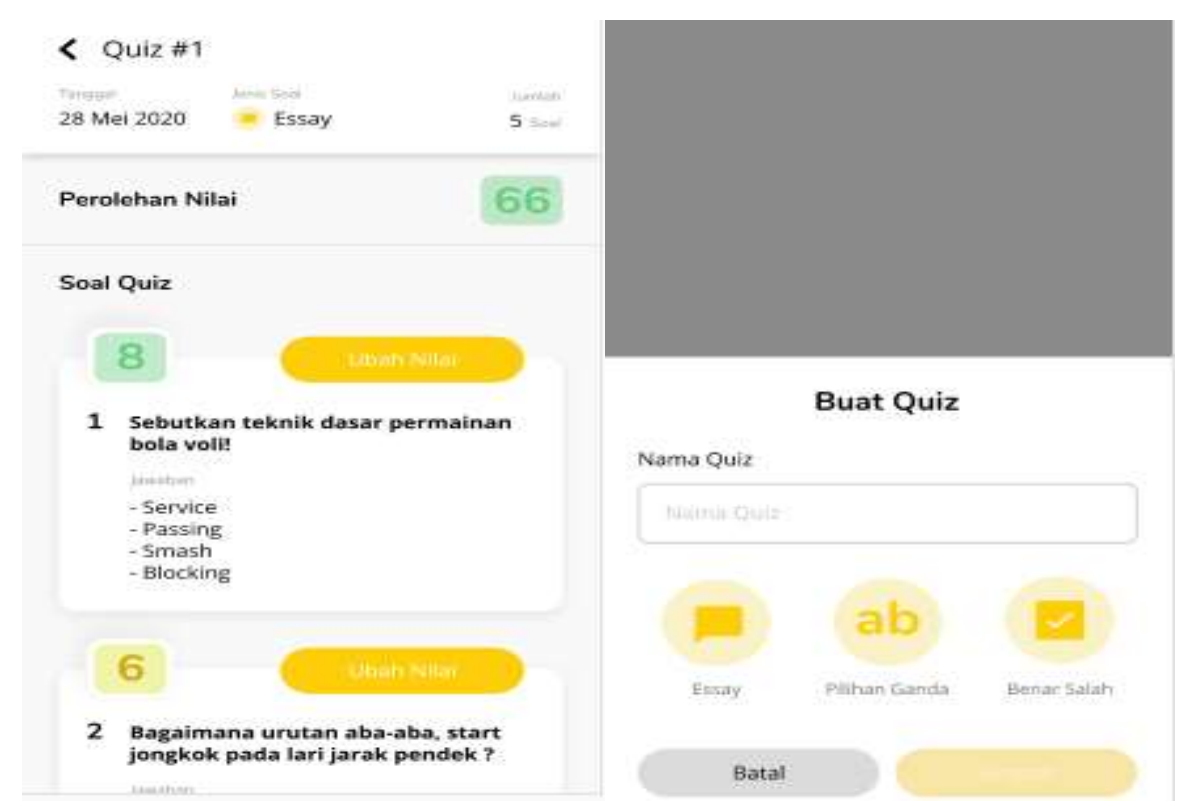

Fig.3. Display of Quiz (cognitive)

Fig.4. Optional type of Quiz 


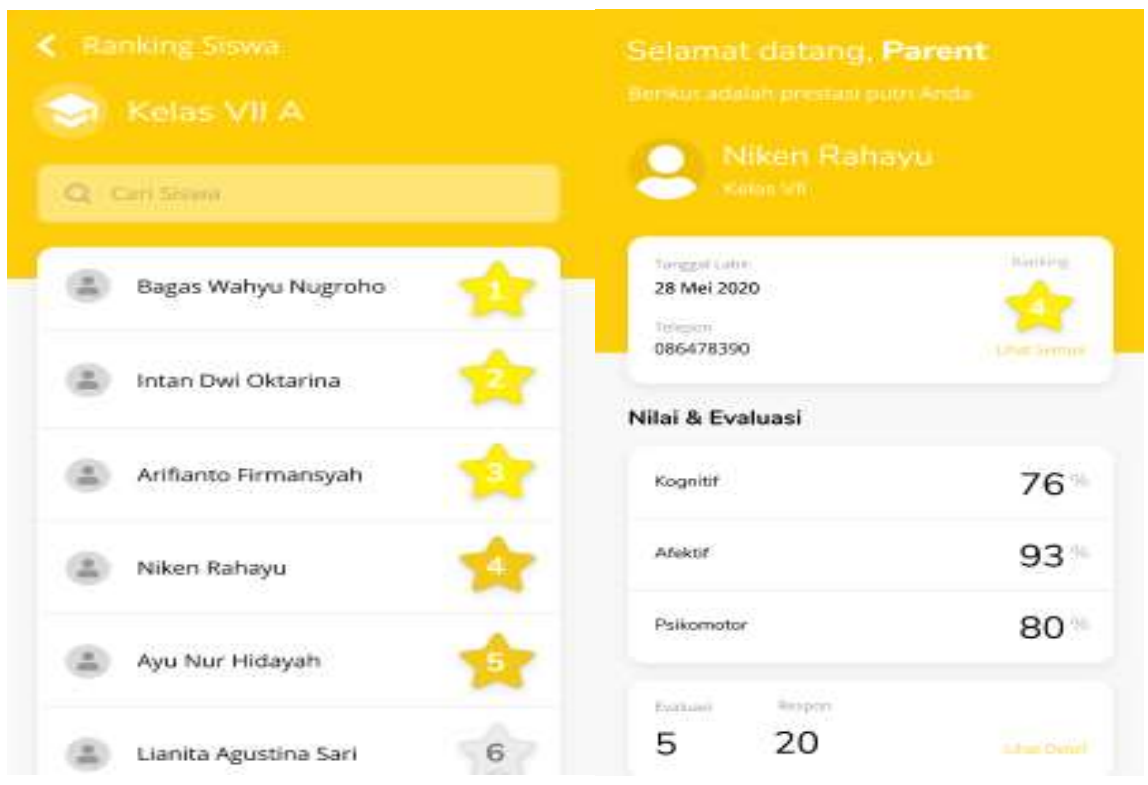

Fig.5. Ranking System

Fig.6. Display for Parents Account

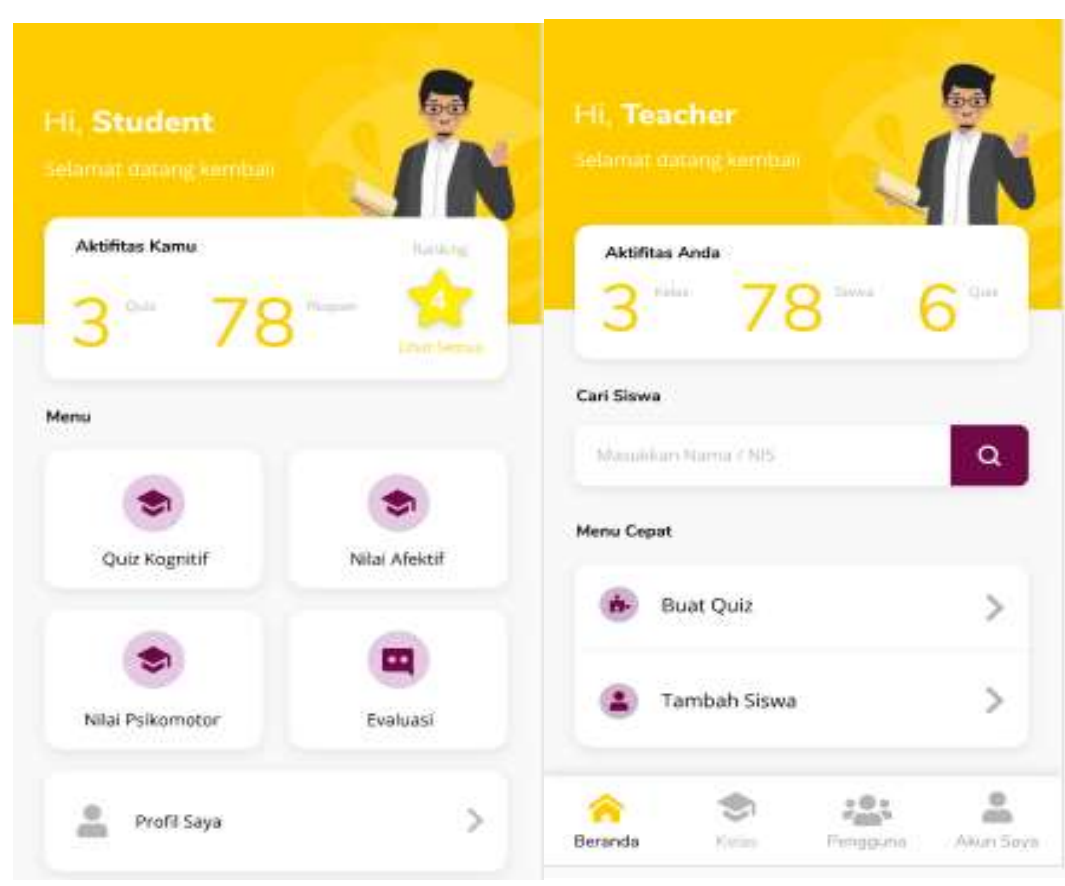

Fig.7. Display for Students Account Fig.8. Display for Teachers Account 


\section{Stage 4: Test the Prototype}

Testing the prototype is carried out by sending the prototype link to the participants and sending a google form link to get an assessment from the participants regarding the usefulness of the design that was made. The following is a list of questions used in data collection:

Questions for PE Teachers:

1) BESCOPER helps teachers provide assessments to students

2) BESCOPER helps teachers evaluate learning activities

3) BESCOPER can save the data on the student performance in terms of knowledge, behavior, and skills in physical education

4) BESCOPER makes it easy for teachers to give reports of student learning outcomes to parents

5) Easy to use

6) Interest in using BESCOPER

Question for students:

1) BESCOPER makes it easy to see learning outcomes

2) BESCOPER facilitates learning in physical education

3) BESCOPER improves the mastery of knowledge, attitudes, and skills

4) BESCOPER helps communication with teachers and parents

5) Easy to use

6) Interest in using BESCOPER

Question for parents :

1) BESCOPER helps see children's learning outcomes

2) BESCOPER facilitates children's learning

3) BESCOPER controls children's learning outcomes

4) BESCOPER helps communication with teachers

5) Easy to use

6) Interest in using BESCOPER

Each question has a rating scale range from 1 - 5:

1: Strongly Disagree

2: Disagree

3: Neutral

4: Agree

5: Strongly Agree

In addition, participants were also given the opportunity to provide suggestions related to the development of prototype in the future in order to become a suitable application to use. 


\section{$4 \quad$ Result}

The apps design took 2 months including creating a basic database, entering a behavior change strategy, including all physical education materials in accordance with the national curriculum for junior high school, design selection, and the platform used up to the prototype testing stage. Here are the results of the first stage test:

Table 1. PE Teacher Response on Phase $1(n=15)$

\begin{tabular}{ccccccccccc}
\hline & \multicolumn{4}{c}{ RANGE SCORE } & \multicolumn{4}{c}{ Percentage Value } \\
\hline Quest & $\mathbf{1}$ & $\mathbf{2}$ & $\mathbf{3}$ & $\mathbf{4}$ & $\mathbf{5}$ & SD & D & N & A & \multicolumn{2}{c}{ SA } \\
\hline & & & 4 & 6 & 5 & & & $27 \%$ & $40 \%$ & $33 \%$ \\
& & & 3 & 7 & 5 & & & $20 \%$ & $47 \%$ & $33 \%$ \\
& & & 3 & 8 & 4 & & & $20 \%$ & $53 \%$ & $27 \%$ \\
& & & 4 & 6 & 5 & & & $27 \%$ & $40 \%$ & $33 \%$ \\
& & & 4 & 5 & 6 & & & $27 \%$ & $33 \%$ & $40 \%$ \\
& & 4 & 8 & 3 & & & $27 \%$ & $53 \%$ & $20 \%$ \\
\hline & & Average & & & & & & $25 \%$ & $44 \%$ & $31 \%$ \\
\hline
\end{tabular}

Table 2. Students Response on Phase $1(n=15)$

\begin{tabular}{|c|c|c|c|c|c|c|c|c|c|c|}
\hline \multirow[b]{2}{*}{ Quest } & \multicolumn{5}{|c|}{ RANGE SCORE } & \multicolumn{5}{|c|}{ Percentage Value } \\
\hline & 1 & 2 & 3 & 4 & 5 & SD & D & $\mathbf{N}$ & A & SA \\
\hline 1 & & & 4 & 5 & 6 & & & $27 \%$ & $33 \%$ & $40 \%$ \\
\hline 2 & & & 3 & 7 & 5 & & & $20 \%$ & $47 \%$ & $33 \%$ \\
\hline 3 & & & 4 & 6 & 5 & & & $27 \%$ & $40 \%$ & $33 \%$ \\
\hline 4 & & & 4 & 6 & 5 & & & $27 \%$ & $40 \%$ & $33 \%$ \\
\hline 5 & & & 3 & 7 & 5 & & & $20 \%$ & $47 \%$ & $33 \%$ \\
\hline 6 & & & 3 & 7 & 5 & & & $20 \%$ & $47 \%$ & $33 \%$ \\
\hline \multicolumn{6}{|c|}{ Average } & & & $24 \%$ & $42 \%$ & $34 \%$ \\
\hline
\end{tabular}

Table 3. Parents Response on Phase $1(n=15)$

\begin{tabular}{|c|c|c|c|c|c|c|c|c|c|c|c|}
\hline \multirow[b]{2}{*}{ Quest } & \multicolumn{6}{|c|}{ RANGE SCORE } & \multicolumn{5}{|c|}{ Percentage Value } \\
\hline & & 1 & 2 & 3 & 4 & 5 & SD & D & $\mathbf{N}$ & A & SA \\
\hline & 1 & & & 3 & 7 & 5 & & & $20 \%$ & $47 \%$ & $33 \%$ \\
\hline & 2 & & & 3 & 8 & 4 & & & $20 \%$ & $53 \%$ & $27 \%$ \\
\hline & 3 & & & 4 & 5 & 6 & & & $27 \%$ & $33 \%$ & $40 \%$ \\
\hline & 4 & & & 4 & 6 & 5 & & & $27 \%$ & $40 \%$ & $33 \%$ \\
\hline & 5 & & & 4 & 5 & 6 & & & $27 \%$ & $33 \%$ & $40 \%$ \\
\hline & 6 & & & 3 & 8 & 4 & & & $20 \%$ & $53 \%$ & $27 \%$ \\
\hline \multicolumn{7}{|c|}{ Average } & & & $24 \%$ & $43 \%$ & $33 \%$ \\
\hline
\end{tabular}


The following are the results of the prototype user response in phase 1 :

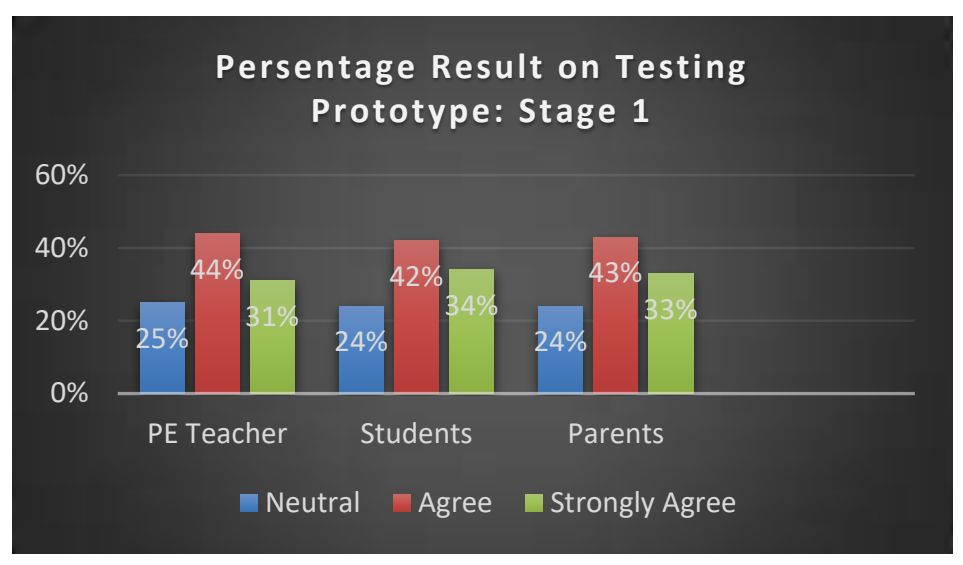

Fig.9. Percentage Result on Phase 1 (Strongly Agree: get average in 33\%)

Based on the results of the Phase 1 test, the highest scores on the Phase 1 test only reached $31 \%$ from teachers, $34 \%$ from students, and $33 \%$ from parents. These results need to be improved in the Phase 2 test with modifications previously made according to the suggestions of users in the Phase 1 test. Following are the results of the data obtained after the Phase 2 test:

Table 4. PE Teacher Response on Phase $2(n=30)$

\begin{tabular}{|c|c|c|c|c|c|c|c|c|c|c|}
\hline \multirow[b]{2}{*}{ Quest } & \multicolumn{5}{|c|}{ RANGE SCORE } & \multicolumn{5}{|c|}{ Percentage Value } \\
\hline & 1 & 2 & 3 & 4 & 5 & SD & D & $\mathbf{N}$ & A & SA \\
\hline & 1 & & 3 & 7 & 20 & & & $10 \%$ & $23 \%$ & $67 \%$ \\
\hline & 2 & & 2 & 10 & 18 & & & $7 \%$ & $33 \%$ & $60 \%$ \\
\hline & 3 & & 4 & 15 & 11 & & & $13 \%$ & $50 \%$ & $37 \%$ \\
\hline & 4 & & 1 & 11 & 18 & & & $3 \%$ & $37 \%$ & $60 \%$ \\
\hline & 5 & & & 12 & 18 & & & & $40 \%$ & $60 \%$ \\
\hline & 6 & & & 8 & 22 & & & & $27 \%$ & $73 \%$ \\
\hline \multicolumn{6}{|c|}{ Average } & & & $5 \%$ & $35 \%$ & $60 \%$ \\
\hline
\end{tabular}

Table 5. Students Response on Phase $2(n=30)$

\begin{tabular}{|c|c|c|c|c|c|c|c|c|c|c|}
\hline \multirow[b]{2}{*}{ Quest } & \multicolumn{5}{|c|}{ RANGE SCORE } & \multicolumn{5}{|c|}{ Percentage Value } \\
\hline & 1 & 2 & 3 & 4 & 5 & SD & D & $\mathbf{N}$ & A & SA \\
\hline & 1 & & & 12 & 18 & & & & $40 \%$ & $60 \%$ \\
\hline & 2 & & 1 & 11 & 18 & & & $3 \%$ & $37 \%$ & $60 \%$ \\
\hline & 3 & & 2 & 10 & 18 & & & $7 \%$ & $33 \%$ & $60 \%$ \\
\hline & 4 & & & 10 & 20 & & & & $33 \%$ & $67 \%$ \\
\hline & 5 & & & 5 & 25 & & & & $17 \%$ & $83 \%$ \\
\hline & 6 & & & 5 & 22 & & & & $17 \%$ & $83 \%$ \\
\hline & & $A v$ & & & & & & $1 \%$ & $30 \%$ & $69 \%$ \\
\hline
\end{tabular}


Table 6. Parents Response on Phase $2(n=30)$

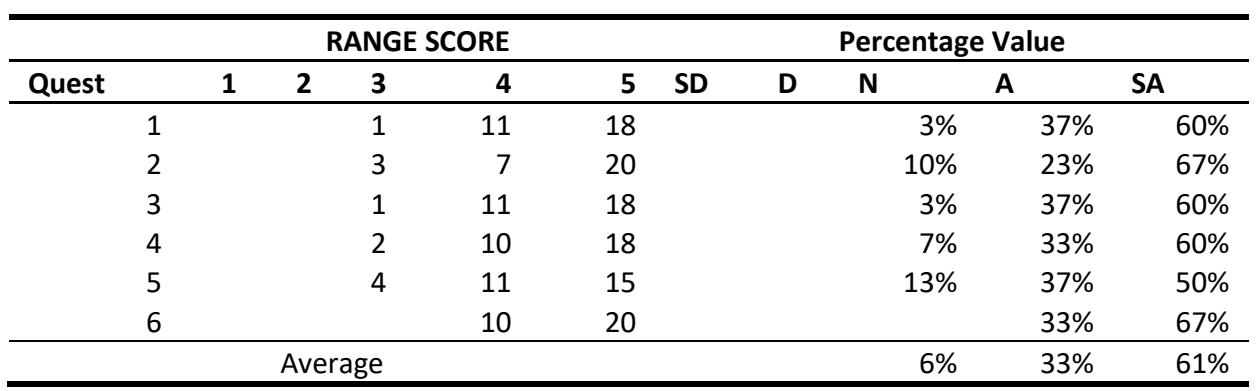

The following are the results of prototype user response in phase 2 :

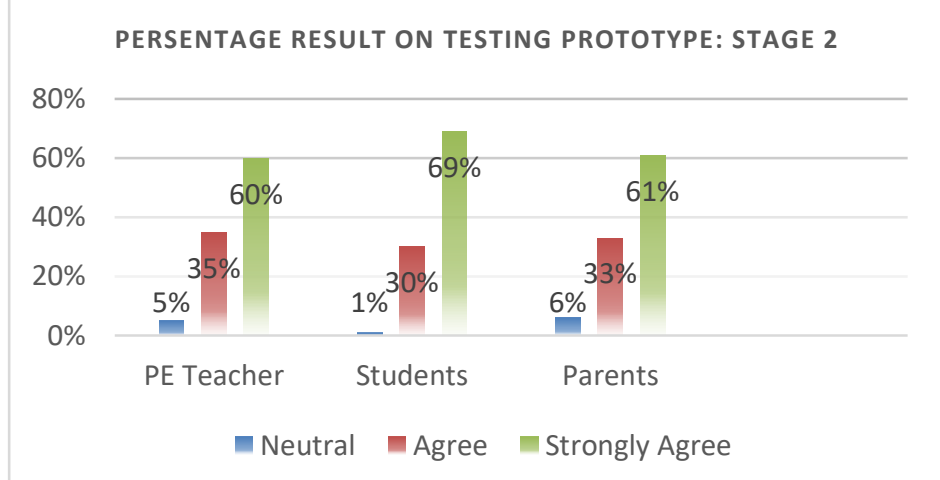

Fig.10. Percentage Result on Phase 2 ( Strongly Agree: get average in 63\%)

Based on the data result phase 2, it was found that there were changes in the response of users and user ratings of prototype design became more visible. From these results it was found that user responses from stage 1 experienced an increase in ratings in stage 2, with the following explanation:

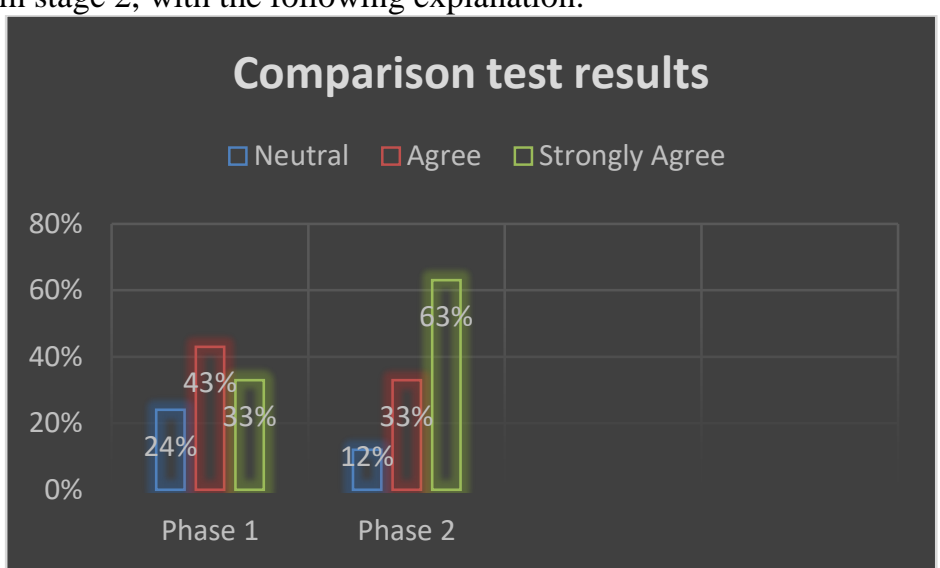


Fig.11. Comparison test results from phase 1 and 2 ( Strongly Agree has increase 30\%)

it can be concluded that the users considered the development of BESCOPER prototype are very useful and could be a new research in the future, especially regarding the assessment of student learning outcomes in physical education for junior high schools, because it was felt to be very helpful to teachers, students and parents in monitoring student's learning outcomes at school. This study was answers the world's challenges that the physical education assessment process can be carried out by developing various types of online-based models. Proven from this prototype test results found of support, positive responses, and hopes to be able to use this application are at $63 \%$ in "Good" criteria.

\section{Conclusion}

Based on these results, it can be concluded that users including physical education teachers, students, and parents strongly support the development of prototypes, and they need that the importance of monitoring the process of student development in learning physical education, especially in the cognitive, affective, and psychomotor domains, and ensuring that students achieve learning goals is the primary basis for users to support this research. The results showed that the interest of users to be able to use this application design is very high, as one of the media for evaluation and assessment of physical education that refers to the development of cellular technology.

\section{Suggestion}

All activities, testing and data analysis on this study, are makes the researcher be able to offer suggestions: Developing prototype for student performance in achieving physical education learning goals, is very important to do, because of seeing the interests and responses of physical education teachers, students and parents that are interested in to use Android-based application products, or similar cellular technologies. In addition, from the results of this study, the research team found that the BESCOPER design could support the subsequent development of research stages to become a multipurpose application in the future.

Acknowledgements This study collaborates with CV. Edukreasi in focus of educational application developers, handled by Iwan Afandhi Yusuf, who directly handled the database processing and prototype design to be developed. This research is also based on the licensing of the Semarang City Education Office, because this research involves several physical education teachers who are members of the junior high school physical education MGMP teacher, Semarang City. All of participants who have helped this research include junior high school students in several schools in the city of Semarang, and parents with entire research team has collaborated to achieve the implementation of this study. 


\section{References}

[1] Domingo MG, Garganté AB. Exploring the use of educational technology in primary education: Teachers' perception of mobile technology learning impacts and applications' use in the classroom. Comput Human Behav 2016;56:21-8.

[2] Penney D, Jones A, Newhouse P, Cambell A. Developing a digital assessment in senior secondary physical education. Phys Educ Sport Pedagog 2012;17:383-410.

[3] Wongwatkit C, Prommool P, Chookaew S, Mee-inta A. A Mobile Web Application for Learning Outcome Evaluation: Analysis and Design of Teacher and Student Interfaces. 2018 Glob. Wirel. Summit, IEEE; 2018, p. 151-5.

[4] Krause JM, O’Neil K, Jones E. Technology in Physical Education Teacher Education: A Call to Action. Quest 2019:1-19.

[5] Keengwe J, Bhargava M. Mobile learning and integration of mobile technologies in education. Educ Inf Technol 2014;19:737-46.

[6] Healey D. Technology Enhanced Learning Environments. TESOL Encycl English Lang Teach 2018:1-6.

[7] Hebden L, Cook A, Van Der Ploeg HP, Allman-Farinelli M. Development of smartphone applications for nutrition and physical activity behavior change. J Med Internet Res 2012;1:e9.

[8] Goad T, Towner B, Jones E, Bulger S. Instructional Tools for Online Physical Education: Using Mobile Technologies to Enhance Learning. J Phys Educ Recreat Danc 2019;90:407.

[9] Richey RC, Klein JD. Design and Development Research. Handb. Res. Educ. Commun. Technol., New York, NY: Springer New York; 2014, p. 141-50.

[10] O'Connor S, Andrews T. Smartphones and mobile applications (apps) in clinical nursing education: A student perspective. Nurse Educ Today 2018;69:172-8. 